\title{
Radiation Induced Grafting of Acrylic Acid onto Viscose Rayon Fabrics and Its After-Effects
}

\author{
M. F. Barakat1*, K. M. El-Salmawy², A. H. Zahran² \\ ${ }^{1}$ Nuclear and Radiological Control Authority, Cairo, Egypt \\ ${ }^{2}$ National Center of Radiation Research and Technology, Atomic Energy Authority, Cairo, Egypt

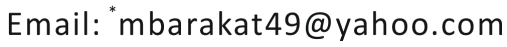

Received 5 July 2016; accepted 28 August 2016; published 31 August 2016

Copyright (C) 2016 by authors and Scientific Research Publishing Inc.

This work is licensed under the Creative Commons Attribution International License (CC BY). http://creativecommons.org/licenses/by/4.0/

(c) (i) Open Access

\begin{abstract}
Radiation induced grafting of various polymers with different monomers proved to be an attractive means to modify the physical or chemical properties of polymeric materials or textile fabrics. In the present work, radiation induced grafting of viscose rayon fabrics, consisting mainly of cellulose fibers, with acrylic acid monomer has been carried out. The grafting yields have been thoroughly studied as a function of different applied experimental parameters. The impact of the graft yield on the physical properties of the fabrics such as tensile strength, elongation, swelling, moisture absorption, crease recovery angle and also the dyeing properties of the fabrics has been studied. The effect of increasing the contact time of the fabric and monomer solution, at room temperature, after stopping irradiation has been studied in detail as well as the effect of temperature on the irradiated samples also after stopping irradiation. The best grafting yield was obtained on irradiating viscose rayon fabric in methanol-water solvent containing acrylic acid monomer, at a dose $20 \mathrm{kGys}$, then heating for 7 hours at $80^{\circ} \mathrm{C}$ and finally keeping the samples at room temperature for about 20 hours. That treatment significantly increased the final graft yield.
\end{abstract}

\section{Keywords}

Viscose Rayon, Copolymerization, Acrylic Acid, Comonomer, Gamma Irradiation, Radiation Grafting, Graft Yield

\section{Introduction}

Radiation induced graft copolymerization of vinyl monomers onto various polymeric materials or textile fabrics "Corresponding author.

How to cite this paper: Barakat, M.F., El-Salmawy, K.M. and Zahran, A.H. (2016) Radiation Induced Grafting of Acrylic Acid onto Viscose Rayon Fabrics and Its After-Effects. Open Journal of Polymer Chemistry, 6, 27-42. 
proved to be a simple and effective means for modifying the chemical and physical properties of various polymeric substrates [1]-[3]. For example, radiation induced graft copolymerization of acrylic acid onto Nylon-6 gave fibers with better dyeability [4]. Grafting of vinyl pyrolidone onto Nylon-6 by gamma radiations has been reported to result in modified fibers with higher moisture regain and tensile properties [5]. Moreover, the wet crease recovery of viscose rayon has been found to improve by grafting with acrylic acid monomer [6]. For better control over the nature of changes occurring in grafted products, in some cases mixed monomers have been applied. Thus, graft copolymers prepared from polypropylene films with mixed monomers e.g. acrylic acid together with styrene, were reported [7].

Viscose rayon is a rather popular synthetic fabric. It would be very useful to investigate the possibility of modifying its physical properties to increase its value as an industrial technical product. Perusal of literature showed that very little data are available in that respect.

In the present work, samples of viscose rayon fabric were grafted with acrylic acid monomer by gamma radiations under different experimental parameters including solvent type and composition, irradiation dose, etc., in a trial to observe the changes in the properties of the modified fabrics, particularly the dyeing properties, as a result of the applied treatments.

\section{Materials and Experimental Techniques}

\subsection{Materials}

\subsubsection{Viscose Rayon}

Untreated pure viscose rayon fabrics were obtained from Misr Helwan company, Helwan, Egypt. Before being used viscose rayon fabrics (in the form of $7 \mathrm{~cm}$ width stripes) were extracted for 30 minutes with diethyl ether then with ethyl alcohol in a Soxhlet apparatus and finally were washed with distilled water. The samples were dried in a vacuum oven at $60^{\circ} \mathrm{C}$ until constant weight. The dried samples were stored in a vacuum descicator until used.

\subsubsection{Monomers}

Acrylic acid was obtained from Prolabo, Rhone, France. It was purified by distillation at $48.5^{\circ} \mathrm{C}$ under reduced pressure $(15 \mathrm{~mm} \cdot \mathrm{Hg})$ in the presence of $5 \%$ hydroquinone as stabilizer.

\subsubsection{Solvents}

Double distilled water was used all over the work. Analar methanol was obtained from Prolabo, Rhone, France.

Dimethyl formamide (DMF), a pure grade product, was obtained from Veb-Laborchemie, Germany and was used without further purification.

Analar benzene was obtained from the B. D. H., GB and used without further purification.

\subsubsection{Solid Inorganic Chemicals}

A. R. Ferrous ammonium sulphate $\left[\left(\mathrm{NH}_{4}\right)_{2} \cdot \mathrm{SO}_{4} \cdot \mathrm{FeSO}_{4} \cdot 6 \mathrm{H}_{2} \mathrm{O}\right]$, Nickel (II) chloride $\left[\mathrm{NiCl}_{2} \cdot 6 \mathrm{H}_{2} \mathrm{O}\right]$ and cobalt (II) sulfate $\left[\mathrm{CoSO}_{4} \cdot 7 \mathrm{H}_{2} \mathrm{O}\right]$ were obtained from B. D. H, GB.

\subsubsection{Dyes}

The following dye types were used in the present work. The direct dye 23, Diamine Fast Scarlet 485, C. I. 2916 and the disperse dye Celliton pink $\mathrm{FF}_{3}$, were obtained from BASF, Germany. The basic dye Sandocryl blue B-3 Gr, C. I. 41004 was obtained from Sandoz Germany.

\subsection{Preparation of Samples for Irradiation}

In the present work, irradiation grafting of viscose rayon fabrics with acrylic acid monomer under different experimental parameters was studied.

For irradiation of samples, pyrex glass tubes were used, $2 \mathrm{~cm}$ in diameter and $15 \mathrm{~cm}$ long, provided with two break seals, one for closing the tubes before irradiation and the other for opening them after irradiation.

In all experiments, exactly about $0.5 \mathrm{~g}$ of viscose rayon samples were introduced into the glass irradiation tubes. Fourty $\mathrm{ml}$ of the liquid phase, consisting of methanol/water or Dimethyl formamide/water, containing a 
certain amount of acrylic acid monomer and 25 micromoles of $\mathrm{Fe}^{2+}$ ions, were finally added taking care that the contents in the irradiation tubes did not exceed two thirds of their total volume. The contents in the tubes were deaerated by bubbling Ar or $\mathrm{N}_{2}$ then were freezed, sealed and introduced into the gamma cell for irradiation.

\subsection{Gamma Irradiation}

A Cobalt-60 Canadian gamma cell 220 of the National Centre For Radiation Research And Technology, Nasr City, Cairo with a dose rate $1.8 \mathrm{kGys} /$ hour was used. Some preliminary studies were carried out using the gamma cell facility placed in the Nuclear Research Center, Physics Department, Inshas, Cairo, with a dose rate 280 grey/hour. The irradiated samples were arranged in a carton rack inside the irradiation volume in order to specify the isodose positions in the irradiation volume inside the cell.

\subsection{Treatment of Irradiated Samples and Determination of the Graft Yield}

At the end of the irradiation period, the tubes were cooled then opened within one hour after their removal from the irradiation field. In those cases where post-irradiation heat treatment or storage of the sealed irradiation tubes was applied, the tubes were opened after the appropriate treatment and the grafted viscose rayon samples were removed, thoroughly washed with hot water, extracted with water in a soxhlet apparatus for three hours then carefully dried and finally weighed. The extraction process was repeated until the grafted samples acquired a constant weight.

The graft yield was then calculated by the equation:

$$
\% \text { Graft yield }=\left\{\left(W_{g}-W_{i}\right) / W_{i}\right\} \times 100 ;
$$

where $W_{i}$ is the initial weight of the viscose rayon sample used and $W_{g}$ is the weight of the grafted viscose rayon sample after washing and drying.

\section{Investigation of the Properties of the Grafted Viscose Rayon Fabrics}

\subsection{Determination of Moisture Absorption (\%)}

The grafted viscose rayon sample was placed in a weighing bottle then dried in a vacuum oven at $100^{\circ} \mathrm{C}-110^{\circ} \mathrm{C}$ for two hours to ensure the complete removal of moisture, then kept to cool in a desiccator. The weight of the dry sample, $W_{d}$, was determined. The weighing bottle containing the dry sample was then kept for 24 hours in a desiccator containing saturated sodium nitrite solution to give $65 \%$ relative humidity at $21^{\circ} \mathrm{C}$. The weight of the wet grafted sample was then determined, $W_{w}$. The percent moisture absorption was then calculated from the following relationship:

$$
\% \text { Moisture absorption }=\left\{\left(W_{w}-W_{d}\right) / W_{d}\right\} \times 100
$$

\subsection{Determination of Swelling (\%)}

The grafted viscose rayon sample was placed in a weighing bottle, completely dried in a vacuum oven then kept to cool in a desiccator and weighed. That process was repeated until constant weight, $W_{d}$. The dry sample was immersed in distilled water for 24 hours then centrifuged for $5 \mathrm{~min}$. at $2000 \mathrm{r} / \mathrm{min}$, carefully removed and finally weighed, $W_{w}$.

The percent swelling was then calculated as follows

$$
\text { \%Swelling }=\left\{\left(W_{w}-W_{d}\right) / W_{d}\right\} \times 100
$$

\subsection{Determination of the Dry Crease Recovery}

The dry crease recovery angle of the grafted samples was determined using a special Hungarian apparatus type FF-07. Measurements were carried out according to the standard ASTM method twice, on the weft and warp directions of the grafted samples. A load was applied for 15 minutes then the load was released and the sample was left free for 15 minutes and the formed angle was finally measured. 


\subsection{Determination of Tensile Strength and Elongation at Break}

The untreated and grafted samples used for tensile strength and elongation at break measurements were tested according to ASTM638 specifications. An Instron Universal tester (GB), was used throughout the present work by applying a crosshead speed of $10 \mathrm{~mm} / \mathrm{min}$ at room temperature with tension and compression capacity of 10 tons. Squared samples were prepared with a side length of $5 \mathrm{~cm}$ and placed between the jaws of the apparatus. Elongation at break and tensile strength were calculated according to the following:

$$
\% \text { Elongation at break }=\left(L-L_{o} / L_{o}\right) \times 100,
$$

where $L_{o}$ is the initial length of the sample between the jaws, $L$ the length after elongation. The stress in $\mathrm{Kg} / \mathrm{cm}^{2}$ was calculated using the equation:

$$
\text { Stress }=\text { force/cross sectional area }
$$

Force was calculated from the resultant chart. The cross sectional area was calculated from the following relationship

$$
\text { Cross sectional area }=\text { Thickness } \times \text { width }
$$

Thickness was measured using a thickness gauge micrometer.

\subsection{Determination of the Dye Uptake by the Grafted Samples}

In the present work, viscose rayon grafted fabric samples were dyed with three types of dyes, a direct dye, a disperse dye and a basic dye. The dyeing procedures used were the standard procedures usually applied for dyeing fabrics with these dyes.

The dye uptake in each case was determined by measuring the color strength of the produced fabrics. Thus, reflectance measurements of the dyed fabrics were carried out using 2 Hunter Lab calorimeter model P-25-M-2. The Kubelka-Munk equation [8] was used to calculate the $K / S$ values as follows:

$$
K / S=(1-R)^{2} / 2 R-\left(1-R_{o}\right)^{2} / 2 R_{o}=A C
$$

where:

$R$ is the decimal fraction of the reflectance of the colored fabric,

$R_{o}$ is the decimal fraction of the reflectance of uncolored fabric,

$K$ is the absorption coefficient; $S$ is the scattering coefficient,

$C$ is the dye concentration; $A$ is a proportionality constant.

\section{Determination of the Acrylic Acid Content in the Liquid Phase Samples after Gamma Irradiation}

The percent of acrylic acid remaining in the irradiation tubes containing the grafting mixture was determined by taking a certain volume of the liquid phase, adding a known excess of standard sodium carbonate solution and at the end of the neutralization reaction, the excess of sodium carbonate was determined by a standard mineral acid solution using methyl orange indicator. From the results it is possible to calculate the amount of acrylic acid remaining after irradiation and also the \% conversion of the monomer. In order to test the validity of the procedure authentic samples were prepared consisting of varying amounts of acrylic acid i.e. 100 - $400 \mathrm{mg}$ in $10 \mathrm{ml}$ water mixed with $90 \mathrm{ml}$ of methanol/water solvent mixture (7:2). The resultant samples were analysed to determine their acrylic acid content as described. The results showed that the percent recovery of acrylic acid in the authentic samples were around $100 \%$.

These results showed that it is possible to determine the percent conversion of acrylic acid in the liquid phase used in the grafting experiments by the described procedure.

\section{Results and Discussions}

Grafting is a highly attractive subject in polymer chemistry since it could lead to the synthesis of new products that acquire desirable physical or technical properties. As a result of the unselective absorption of gamma radiation in matter it is possible to combine any monomer with any polymer just by applying the appropriate irradia- 
tion conditions [9].

In the present work, radiation induced grafting of acrylic acid monomer onto viscose rayon fabric, has been studied in detail.

\subsection{Factors Affecting the Grafting Yields of Acrylic Acid onto Viscose Rayon}

1) Effect of acrylic acid monomer concentration in different solvent systems

The change of the graft yield of acrylic acid monomer onto viscose rayon fabric at different monomer concentrations, in two liquid solvents are shown in Figure 1. It is clear that on using methanol/water solvent mixture, the graft yield increased on increasing acrylic acid concentration up to $10 \%$ and then continues to increase, but at a lower rate up to $20 \%$ monomer concentration.

In case of DMF-water solvent system, the graft yield (\%) was markedly lower than in case of methanol-water solvent system within the monomer concentration range 5\% - 20\% in the liquid phase. That lower graft yield could be mainly due to the decreased swelling of the viscose rayon fibers in DMF-water solvent which is accompanied with greater homopolymer formation than in case of using methanol-water solvent.

In fact on using monomer concentrations greater than $20 \%$ in both solvents excessive gelling occurred due to enhanced homopolymer formation which was difficult to remove efficiently.

2) Effect of solvent type and solvent composition

Solvents play an important role in radiation induced grafting of monomer molecules on to the active sites formed in the solid polymer matrix, by gamma irradiation. These active sites interact readily with the approaching monomer molecules from the bulk solution by diffusion. The diffusion process is enhanced mainly by the swelling of treated fabrics under the effect of the existing solvent system. In the present work, methanol-water and DMF-water solvent systems were used.

The change of the acrylic acid graft yield (\%) on using different solvent systems with variable compositions, at different irradiation doses, are shown in Figure 2(A) and Figure 2(B). It is possible to observe that the grafting yield of acrylic acid onto viscose rayon increases on increasing the methanol concentration in solvent up to 80\%and then decreased.

On using DMF as the solvent system the graft yields were found to decrease on increasing DMF up to $25 \%$ then remained almost unchanged until the concentration of DMF amounted to $90 \%$, on using two different irradiation doses. That behavior could be attributed to differences in the ability of those two solvent systems to swell the fibers and probably shows that methanol/water solvent system is more capable of swelling viscose rayon fibers than DMF/water system.

3) Effect of Irradiation dose

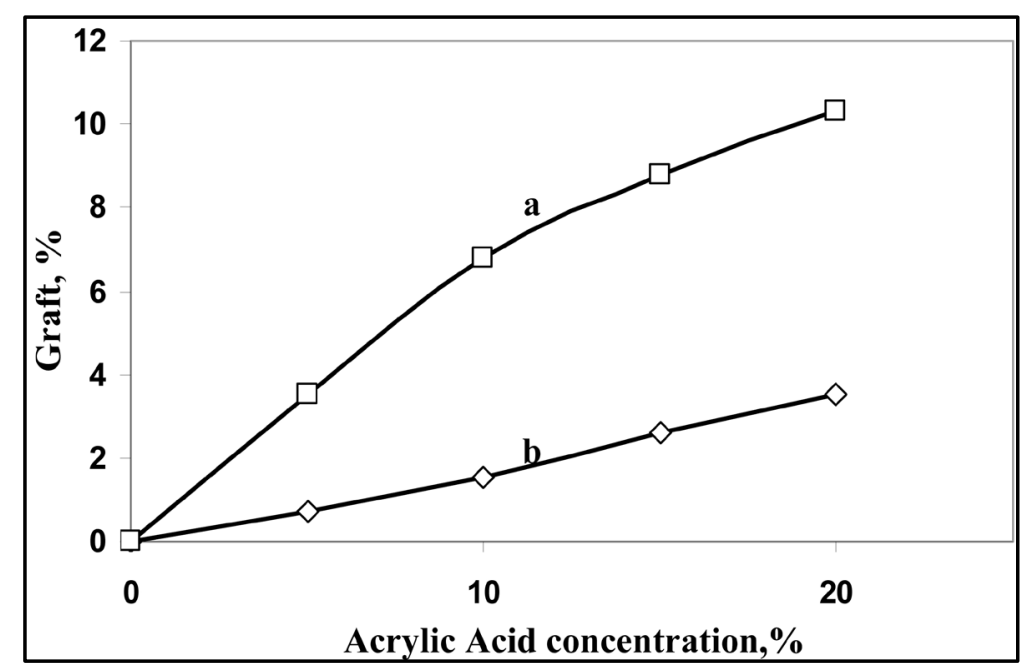

Figure 1. Effect of monomer concentration on grafting acrylic acid onto viscose rayon fabric using different solvent systems containing 25 micromoles of $\mathrm{Fe}^{2+}$ : a-Methanol-water mixture (7:2); b-Dimethyl formaide-water mixture (6:3). Irradiation dose: $20 \mathrm{kGy}$. 


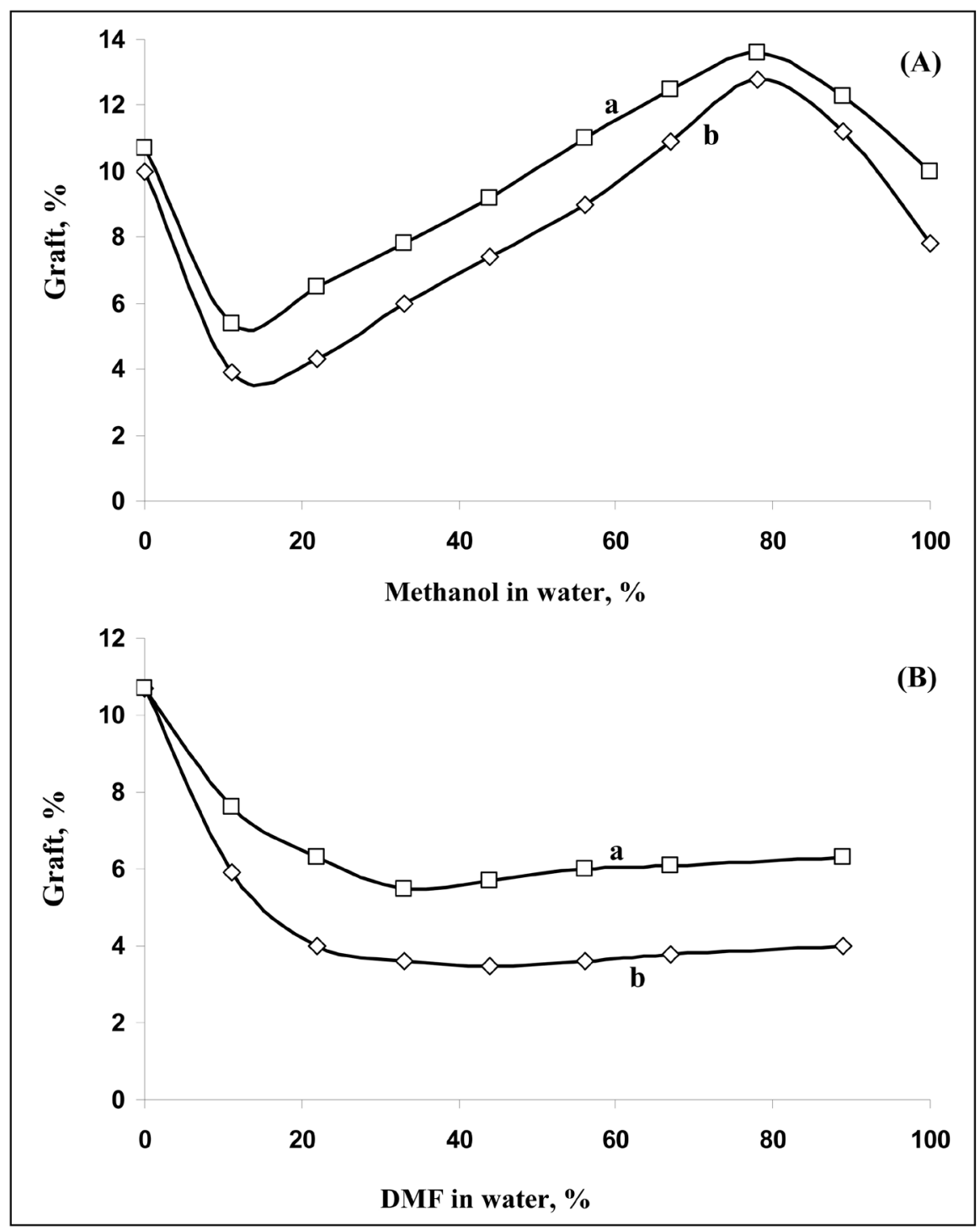

Figure 2. Effect of solvent composition on the graft yield of acrylic acid onto viscose rayon fabrics. Monomer concentration in the solvent used, $10 \%$. Irradiation dose: a-20 kGy. b10 kGy. Solvents systems, containing 25 micro moles of $\mathrm{Fe}^{2+}$ : (A) Methanol-water solvent; (B) DMF-water solvent.

Viscose rayon samples were irradiated in different liquid phases containing $10 \%$ acrylic acid and $90 \%$ of each of two solvent systems, namely Methanol-water (7:2) and DMF-water (1:8) in presence of 25 micromoles of $\mathrm{Fe}^{2+}$ ions. The results are shown in Figure 3 from which it could be observed that the grafting yields did not significantly increase on increasing the gamma irradiation doses from $10 \mathrm{kGy}$ up to $40 \mathrm{kGys}$. It is expected that the number of graft centers, formed on vicose rayon depends on the size of the irradiation dose. At higher doses more grafting centers are formed in and on the irradiated fiber. In presence of solvents that do not favor swelling of the fibers to promote the grafting reaction, homopolymer formation is favored. In other words, homopolymer formation increased while the grafting reaction did not increase on increasing the irradiation dose. In the present work, the graft yield increased from $10.5 \%$ to $12 \%$ on using Methanol-water solvent system and from 5.5\% to $7 \%$ on using DMF-water solvent, on increasing the irradiation dose from 10 to $40 \mathrm{kGy}$. In general, homopolymer formation was markedly observed, particularly on using DMF/water solvent when doses greater than 30 kGy were applied.

4) Effect of presence of air or argon on the graft yield 


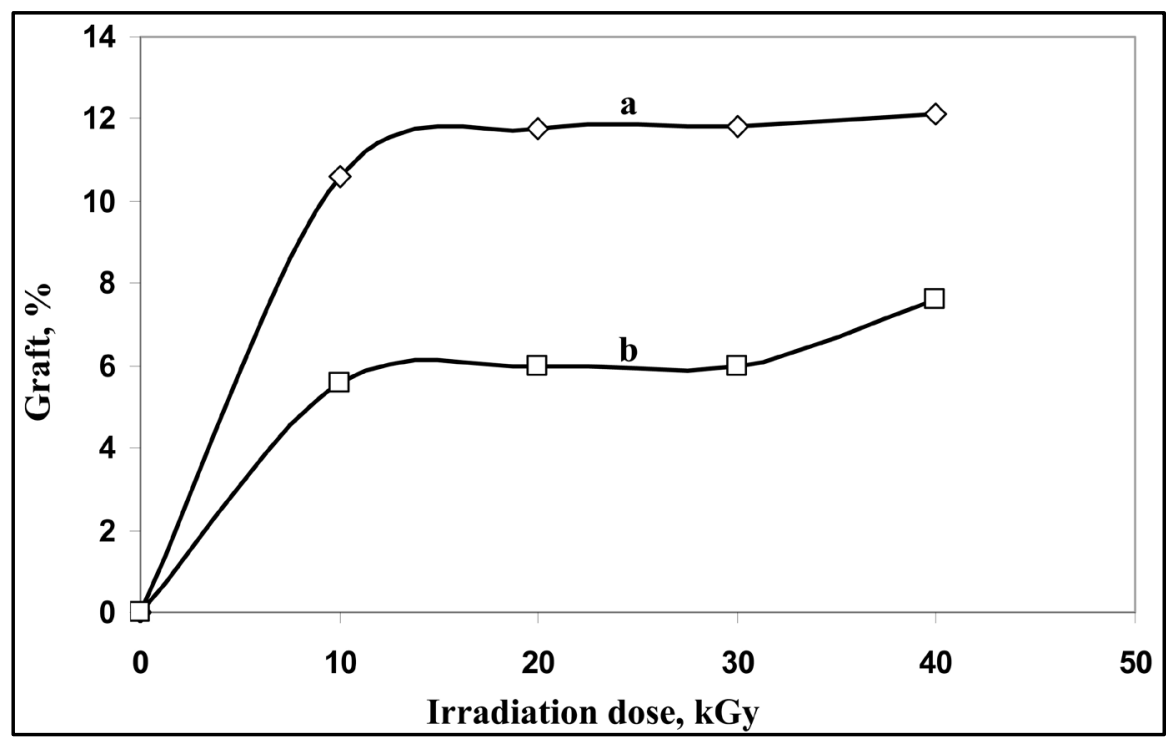

Figure 3. Effect of the $\gamma$-irradiation dose on the grafting yield of acrylic acid onto viscose rayon in different solvent systems: Solvents used: a-Methanol-water (7:2); b-DMFwater (1:8). Monomer concentration: $10 \%$.

The percent grafting of acrylic acid onto viscose rayon fabrics has been determined in two irradiated samples with methanol-water and DMF-water solvent systems. The irradiation tubes were flushed with Argon or air before sealing. It has been found that very slight differences were observed in the grafting yields recorded in both cases.

5) Effect of polyvalent metallic ions on the grafting yield at different irradiation doses

The effect of redox systems involving the use of $\mathrm{Fe}^{2+}$ ions during radiation induced grafting of polymers with vinyl monomers has been reported by many authors to reduce homopolymer formation [10]-[12].

In the present work, a trial has been carried out to investigate the effect of other multivalent metal ions e. g. $\mathrm{Co}^{2+}$ or $\mathrm{Ni}^{2+}$ ions on the grafting yields obtained. Thus, the graft yield obtained on using increasing micromolar amounts of $\mathrm{Fe}^{2+}, \mathrm{Co}^{2+}$ or $\mathrm{Ni}^{2+}$ ions to the irradiated samples, are shown in Figure 4. It could be observed that, in presence of $\mathrm{Co}^{2+}$ ions the maximum percent grafting was 1.8 times greater than the corresponding values obtained in the absence of these ions. In presence of $\mathrm{Ni}^{2+}$ and $\mathrm{Fe}^{2+}$ the maximum grafting yields amounted respectively to 1.46 and 1.29 times greater than the corresponding grafting yields obtained in the absence of these ions.

It has been reported that irradiation of polymer molecules in presence of air leads to the formation diperoxides and hydroperoxides in addition to other products. In presence of $\mathrm{Fe}^{2+}$ these dissociate to give active free radicals:

$$
\begin{aligned}
& \mathrm{P}-\mathrm{O}-\mathrm{O}-\mathrm{P}+\mathrm{Fe}^{2+} \rightarrow \mathrm{PO}^{\bullet}+\mathrm{PO}^{-}+\mathrm{Fe}^{3+} \\
& \mathrm{P}-\mathrm{O}-\mathrm{O}-\mathrm{H}+\mathrm{Fe}^{2+} \rightarrow \mathrm{PO}^{\bullet}+\mathrm{OH}^{-}+\mathrm{Fe}^{3+}
\end{aligned}
$$

The grafting reaction occurs by diffusion of monomer molecules to the active centers PO formed in the polymer structure

$$
\mathrm{PO}^{\bullet}+\mathrm{M} \rightarrow \mathrm{P}-\mathrm{O}-\mathrm{M}
$$

In presence of $\mathrm{Fe}^{2+}$ ions the following reaction can compete for $\mathrm{PO}^{\bullet}$ as follows

$$
\mathrm{PO}^{\bullet}+\mathrm{Fe}^{2+} \rightarrow \mathrm{PO}^{-}+\mathrm{Fe}^{3+}
$$

Therefore, in presence of high redox ions concentration, lower grafting yields will be obtained.

The higher grafting yields obtained in presence of micromole amounts of $\mathrm{Co}^{2+}$ ions, as compared to the yields obtained on using $\mathrm{Fe}^{2+}$ ions, could be understood by referring to the standard reduction potentials of $\mathrm{Co}^{2+}(+1.82$ v) and $\mathrm{Fe}^{2+}(+0.77 \mathrm{v})$ which shows that ferrous ions are stronger reducing agents than cobalt ions. Therefore, the grafting reaction (3) is more favored in presence of $\mathrm{Co}^{2+}$ ions while in presence of $\mathrm{Fe}^{2+}$ ions reaction (4) is more favored. 


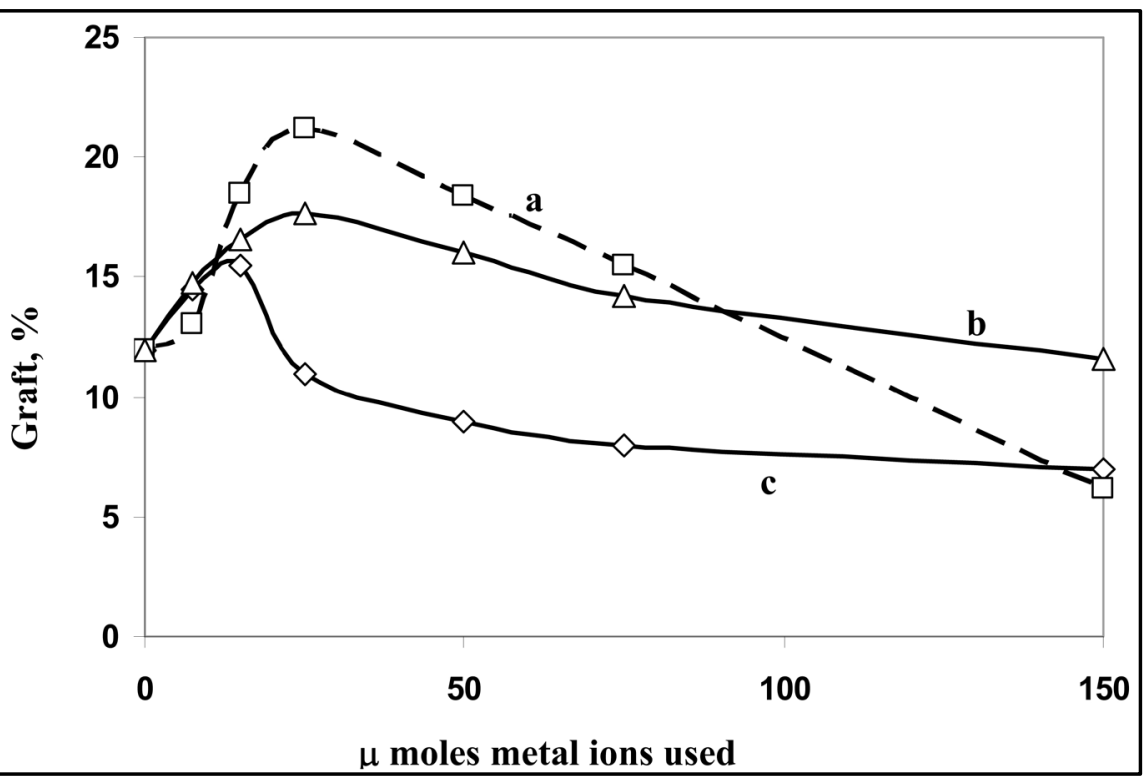

Figure 4. Effect of polyvalent metal ions on the grafting yield of acrylic acid onto viscose rayon. Irradiation dose $20 \mathrm{kGy}$. Solvent system used: 10\% Acrylic acid, 90\% Methanol: $\mathrm{H}_{2} \mathrm{O}(7: 2)$ containing increasing micromolar amounts of: $\mathrm{a}-\mathrm{Co}^{2+}$ ions; $\mathrm{b}-\mathrm{Ni}^{2+}$ ions; $\mathrm{c}-$ $\mathrm{Fe}^{2+}$ ions.

Under these conditions termination of the grafting reaction can occur as a result of $\mathrm{Fe}^{3+}$ accumulation [13] as follows:

$$
\mathrm{Fe}^{3+}+\mathrm{P}-\mathrm{CH}_{2}-(\mathrm{H})(\mathrm{X}) \mathrm{C} \cdot-----\mathrm{P}-\mathrm{CH}=(\mathrm{H})(\mathrm{X}) \mathrm{C}+\mathrm{Fe}^{2+}+\mathrm{H}^{+}
$$

Obviously $\mathrm{Co}^{3+}$ ions accumulate in the irradiated systems relatively to a lower extent than $\mathrm{Fe}^{3+}$ and consequently the termination reaction in case of cobalt ions occurs at a lower yield.

6) Effect of storage time of the grafted samples after irradiation

After irradiation the sealed tubes containing viscose rayon fabric samples, monomer and solvent were kept at room temperature for increasing time periods. The tubes were then opened and the grafted samples were, repeatedly washed with hot water, dried and weighed until constant weight. The grafting yields were calculated The results obtained are shown in Figure 5. It is clear that on using methanol-water solvent system, the initial percent grafting, amounting to $14 \%$, decreased gradually to about $3 \%$, at 28 hours after stopping irradiation. As the storage time was further increased the percent grafting was found to increase gradually to $22 \%$ when the irradiated samples were kept for 120 hours after stopping irradiation.

It is very probable that the observed change in the grafting yield during the first 28 hours after irradiation is the result of two processes viz. a decay process of the original graft copolymer A formed during irradiation and which decays completely in 28 hours after stopping irradiation and the graft copolymer B that continue formation even after the complete decay of the copolymer A. The decay curve of copolymer A, shown by line A in Figure 5, is determined by finding the difference between the decay line $(A+B)$ representing the decay of the existing graft copolymer after stopping irradiation and the extrapolated line B representing the increase of the percent yield of copolymer B during its formation, after stopping irradiation.

Therefore, it is possible to conclude that two copolymers A and B coexist for about 28 hours after irradiation and after decay of copolymer A copolymer B continues formation. Such a behavior could be understood if we refer to the nature of the reactive free radical sites formed on the solid viscose rayon matrix upon gamma irradiation.

Viscose rayon consists mainly of cellulose macromolecules (94\%) in the form of long chains containing crystalline, partly crystalline and amorphous regions [14]. The free radicals formed in the amorphous region are readily accessible to the monomer molecules or radicals formed during irradiation. It seems that their interaction is probably reversible as could be observed from the results shown in Figure 5. On the other hand, radicals formed in the ordered matrix of the crystalline regions in viscose rayon fibers are more firmly trapped due to the 


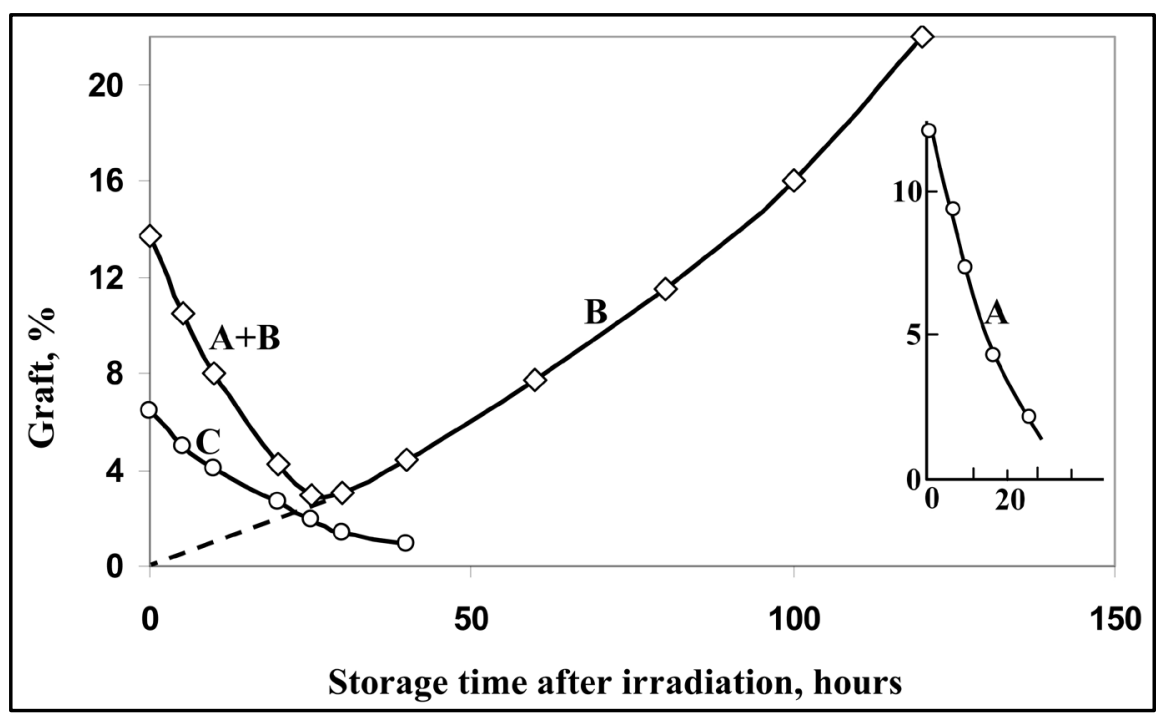

Figure 5. Change of the percent graft of acrylic acid onto viscose rayon with time of storage of samples at room temperature after irradiation. The liquid phase consists of $10 \%$ acrylic acid, 90\% methanol water mixture (7:2) or DMF-water mixture (6:3) and 25 micromoles of $\mathrm{Fe}^{2+}$. Irradiation dose: $20 \mathrm{kGy}$. A + B: Decay curve of the graft, formed during irradiation of viscose rayon fabric in presence of a liquid phase consisting of $10 \%$ acrylic acid and $90 \%$ methanol/water solvent mixture, after stopping irradiation. A-Decay Curve of grafted polymer A initially formed during gamma irradiation with the time of storage after irradiation. C-Decay curve of the grafted viscose rayon with acrylic acid in liquid phase consisting of $10 \%$ acrylic acid, $90 \%$ DMF-water mixture (6:3).

lower mobility of the polymeric segments. Their participation in the grafting reaction is rather slow since the fabrics has to swell to assist the diffusion process of the monomer entities to the active centers in the crystalline matrix to be grafted.

Moreover, during and after irradiation the liquid phase is rendered more viscous. Under such conditions the gel effect becomes more pronounced [15] and the formed radicals do not lose their reactivity but acquire longer life time and can remain trapped for extremely long periods, of the order of several days or even several months [16]. That behavior is encountered in systems which polymerize in a heterogeneous system containing acrylic acid, as in our work.

It is possible to conclude that grafting in the amorphous regions most probably leads to unstable copolymers in the medium and the reaction itself seems to be reversible, which is the case observed in copolymer A while grafting in crystalline regions probably leads to more stable graft copolymers due to their occurrence in an organized matrix of viscose rayon structure. However, the grafting reaction within the crystalline matrix occurs rather slowly to cope with the slow diffusion process of the monomer radicals through the ordered viscose rayon fabric matrix before being trapped.

On using DMF-water solvent together with viscose rayon and acrylic acid, the initial percent grafting gradually decreased until it became negligible 48 hours after the end of irradiation as could be observed in Figure 5. On increasing the storage time no further increase in the grafting yield was observed. This indicates that copolymer B was not formed when DMF-water solvent system was used. This could probably be explained by the fact that the solvent used does not sufficiently swell viscose rayon and that in turn reduces the accessibility of the embedded radicals in the crystalline regions of the solid ordered matrix to the monomer long living radicals in the viscous liquid phase.

In order to test the effect of polyvalent metal ions such as $\mathrm{Co}^{2+}$ on the grafting yield of acrylic acid onto viscose rayon after giving the required irradiation dose and storage, the previous experiment was repeated with the addition of 25 micromoles $\mathrm{Co}^{2+}$ to the irradiated solution. The results obtained are shown in Figure 6.

These results clearly show that the general behavior was quite similar to the behavior shown in Figure 5 . However, the percent grafting yields recorded were higher than the corresponding yields when $\mathrm{Fe}^{2+}$ ions were present. This again demonstrated the accelerative effect of $\mathrm{Co}^{2+}$ on the grafting process. Moreover, copolymer A 


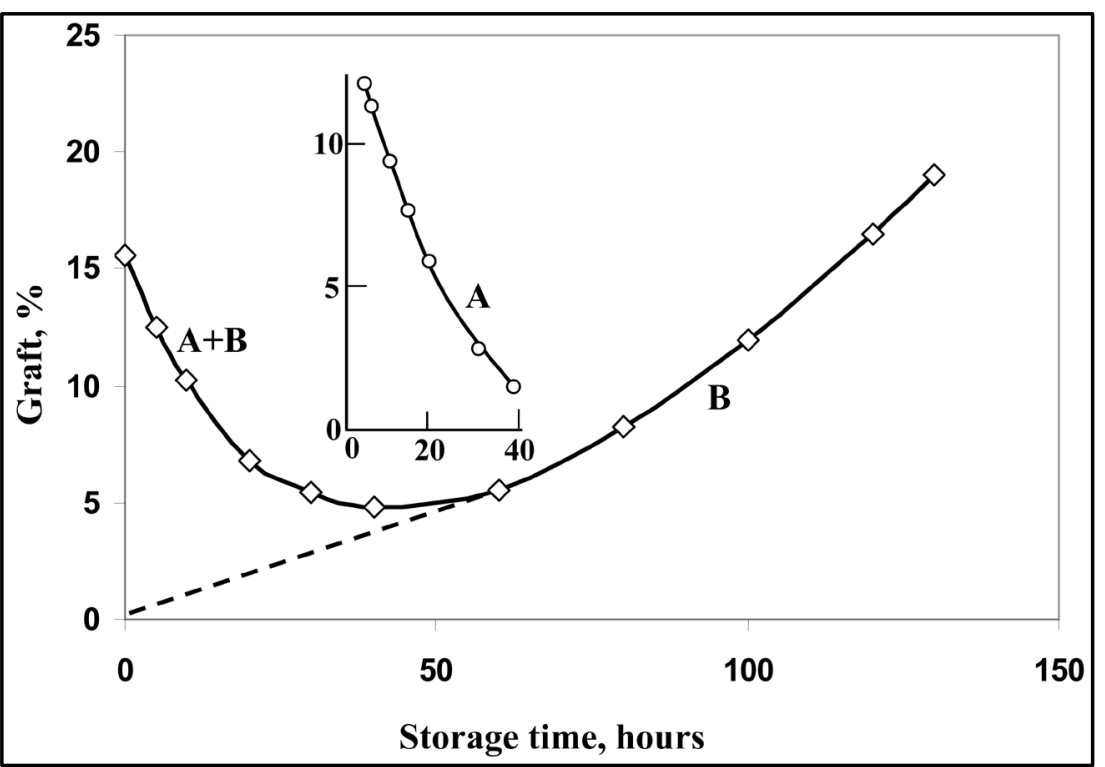

Figure 6. Change of the percent grafting yield of acrylic acid onto viscose rayon with time of storage of samples after irradiation at room temperature, in presence of 25 micromoles $\mathrm{Co}^{2+}$ ions. Irradiation dose: $20 \mathrm{kGy}$ : A + B: Decay curve of the graft formed during irradiation of viscose rayon fabric in presence of $10 \%$ acrylic acid and $90 \%$ of methanol/water solvent system (7:2) and 25 micromoles of $\mathrm{Fe}^{2+}$. The tubes were subjected to a gamma irradiation dose of $20 \mathrm{kGys}$ after stopping irradiation. B-Formation curve of the acrylic acid graft formed after stopping irradiation. A-Decay Curve of the grafted polymer A initially formed during gamma irradiation with time of storage after irradiation.

is formed in presence of cobalt ions to a greater extent than in the presence of $\mathrm{Fe}^{2+}$ ions and at the same time the yield of copolymer $\mathrm{B}$ was less in presence of cobalt ions than in presence of $\mathrm{Fe}^{2+}$ ions.

Percent conversion of acrylic acid monomer in the irradiated viscose rayon samples during grafting

The per cent conversion of acrylic acid monomer in the irradiated samples was determined by acid base back titration of an aliquot of the liquid phase taken from the irradiated samples that were kept for increasing time intervals before analysis. The residual amounts of acrylic acid were almost the same in all samples and did not show any significant change with storage time after stopping irradiation. Thus $38 \pm 1 \mathrm{mg}$ of acrylic acid per ml were found in the liquid phases of the irradiated samples that originally contained $105 \mathrm{mg}$ of acrylic acid per ml. The percent conversion amounted to 64\%. On irradiating the liquid phase alone under the same experimental conditions, the percent conversion of acrylic acid amounted also to 63\%. This clearly shows that while the percent monomer conversion is almost constant and depends only on the irradiation dose, the graft copolymer formation process is not only dependant on the irradiation dose but is also dependant on the time of contact of viscose rayon fibers with the liquid phase after being mutually irradiated and removed from the irradiation field This shows that the graft copolymer B continues formation after stopping irradiation due the continued interaction between the long living free radicals in the irradiated viscose rayon samples and the entrapped free radicals that remained reactive in the irradiated viscous liquid phase.

7) Effect of the thermal treatment of samples after irradiation

After irradiating the viscose rayon samples together with the liquid phase consisting of 10\% Acrylic acid and 90\% methanol-water solvent system (7:2) and using a dose $20 \mathrm{kGys}$, the sealed irradiation tubes were heated at different temperatures for 8 hours and then the graft yields were determined. From the results shown in Figure 7 , it could be observed that the graft yield increased on heating the irradiated tubes at $50^{\circ} \mathrm{C}, 70^{\circ} \mathrm{C}$ and $90^{\circ} \mathrm{C}$ by $16 \%$, $25 \%$ and $58 \%$ respectively as compared to cold samples.

The same experiments were repeated but with the addition of 25 micromoles of $\mathrm{Co}^{2+}$ to the samples to be irradiated. The results are shown in Figure 8. It could be observed that on heating at $50^{\circ} \mathrm{C}$ for four hours the percent grafting was found to increase by $30 \%$ as compared to the graft yield obtained without heating. On further heating for another four hours no significant changes in the graft yield was observed. On the other hand, on heating at $70^{\circ} \mathrm{C}$ and $90^{\circ} \mathrm{C}$, extensive homopolymerization occurred. 


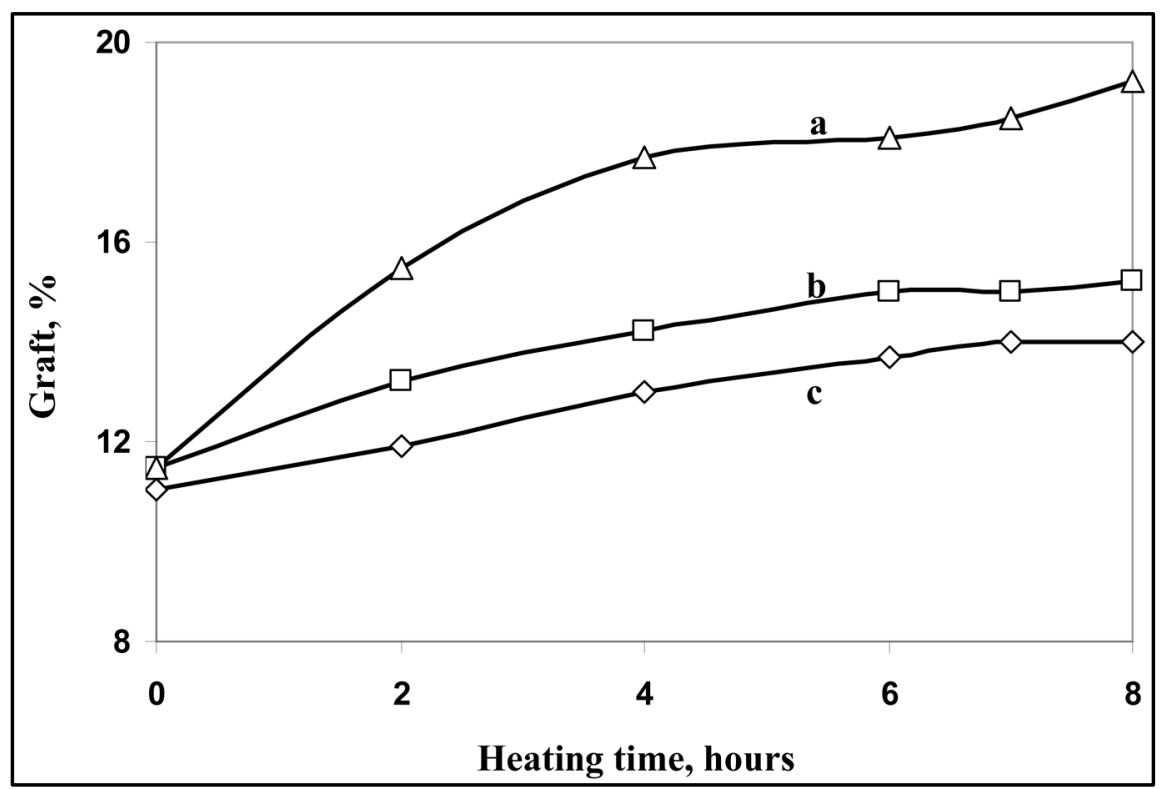

Figure 7. Effect of post-irradiation thermal treatment of irradiated viscose rayon samples grafted with acrylic acid. The liquid phase: $10 \%$ Acrylic acid, 90\% Methanol-water mixture (7:2) and 25 micro moles of $\mathrm{Fe}^{2+}$. Irradiation dose $20 \mathrm{kGy}$ : Samples were heated at: $95^{\circ} \mathrm{C}$ (a), $70^{\circ} \mathrm{C}(\mathrm{b})$ and $50^{\circ} \mathrm{C}$ (c).

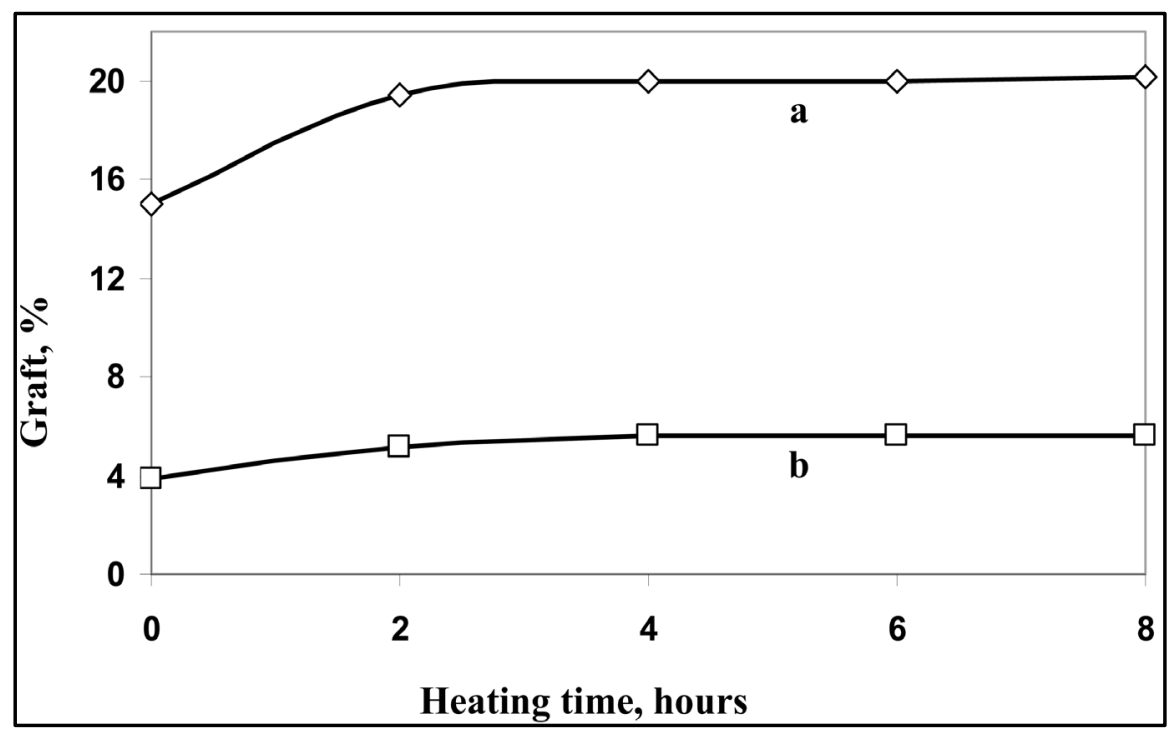

Figure 8. Effect of post-irradiation thermal treatment $\left(\right.$ at $\left.50^{\circ} \mathrm{C}\right)$ on the graft yield of acrylic acid onto viscose rayon in the liquid phase consisting of $10 \%$ acrylic acid and $90 \%$ methanol: $\mathrm{H}_{2} \mathrm{O}$ solvent (7:2) containing 25 micromoles $\mathrm{Co}^{2+}$ ions. Irradiation dose: $20 \mathrm{kGy}$. aImmediately after irradiation; b-48 hours after irradiation.

When the irradiated ampoules were kept for 48 hours after irradiation and then were heated for four hours at $50^{\circ} \mathrm{C}$ the percent graft increased to be $40 \%$ greater than when no heating was applied, as could be also observed in Figure 8.

In partly crystalline and partly amorphous materials, such as cellulose and viscose rayon it is known that the free radicals formed within the crystalline regions are usually more firmly trapped [17] and consequently they readily react at elevated temperatures when most of the crystallites melt. This is not the case with radicals formed in the amorphous regions which can readily participate in many chemical processes such as grafting [18]. 
The marked increase in the graft yield on heating the irradiated heterogeneous systems, depends on the possibility that the monomer molecules can more easily diffuse to the active free radical sites formed upon irradiation within the viscose rayon fibers. This process is facilitated by swelling of the polymer chains in the existing solvent.

Reactions involving free radicals are sensitive to temperature which affects the mobility of the radicals [19]. In addition, heating increases the swelling of the fibers and that increases the accessibility of the deeply seated free radical sites within the fibers to the diffusing monomer molecules. This probably explains the continuation of the grafting reaction after stopping gamma irradiation and heating afterwards.

It could be concluded that the increase in the grafting yield with time could be mainly attributed to the occurrence of the grafting reaction among the crystalline regions in viscose rayon due to the increased diffusion of monomer solvent combinations within the fibers to reach the deeply embedded radicals when the samples were thermally treated after irradiation.

8) Effect of heating and storage time on the grafting yields

It was interesting to investigate the combined effects of both heat and storage time on the grafting yields of acrylic acid on viscose rayon fabrics. Thus, certain weights of viscose rayon fabrics were placed in irradiation tubes together with $10 \mathrm{ml}$ of a solvent system consisting of $10 \%$ acrylic acid and $90 \%$ of methanol/water solvent mixture (7:2) and 25 micromoles of $\mathrm{Fe}^{2+}$. The tubes were subjected to a gamma irradiation dose $20 \mathrm{kGys}$. After irradiation the sealed tubes were placed in a regulated water bath kept at $80^{\circ} \mathrm{C}$ for 7 hours. After heating the samples were kept at room temperature for increasing time intervals. The graft yields were afterwards determined in each of the samples. The results are shown in Figure 9. It is clear that the graft yield increased gradually up to a maximum value at $37 \%$ after about 50 hours heating as compared to about $11 \%$ when no heating or storage of samples were applied. The marked increase in the grafting yield could again be attributed to the increased fiber swelling which increases the accessibility of the deeply seated free radicals within the fibers to the diffusing monomer molecules or radicals. Under the applied experimental conditions heating enhances the mobility of free radicals formed in the monomer molecules which in turn affects the overall grafting yield. The observed decrease in the grafting yield after 75 hours of storage of samples was accompanied with a marked degradation in the quality of the viscose rayon fabric and is accompanied with an increase in the viscosity of the liquid phase due to increased homopolymer formation.

\subsection{Effects of the Grafting Yields on the Physical Properties of Viscose Rayon Fabrics Grafted with Acrylic Acid}

The changes of the physical properties of the grafted viscose rayon fabrics have been studied. The results are

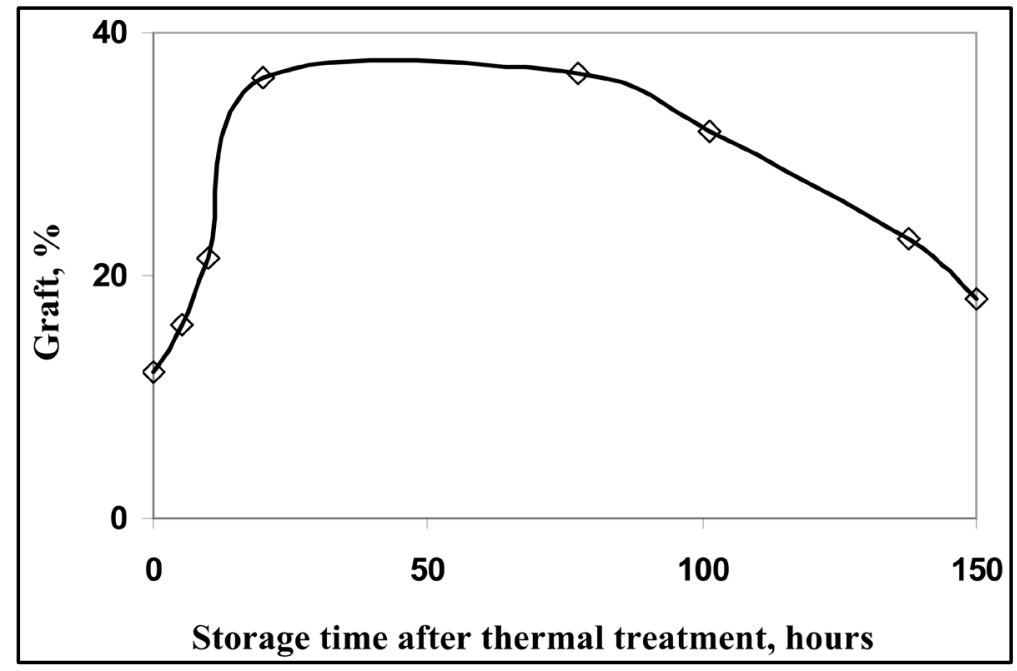

Figure 9. Change of the graft yield of acrylic acid onto viscose rayon samples, heated for 7 hours at $80^{\circ} \mathrm{C}$ after irradiation $(20 \mathrm{kGy})$ then kept for increasing time periods at room temperature. Graft yield (\%) after irradiation: $10.6 \%$. 
given in the following:

1) Swelling (\%) and moisture absorption \%

Figure 10 shows the change of swelling (\%) or moisture absorption (\%) on increasing the graft yield (\%). In methanol-water solvent swelling increased from $72 \%$ to $83 \%$ with a graft yield of $15 \%$ while moisture absorption slightly decreased from $7 \%$ to $5.9 \%$. On using DMF-water solvent, swelling and moisture absorption sharply decreased with the graft yield more than $10 \%$.

2) Tensile strength and elongation

Figure 11 shows that on increasing the graft \% by about $10 \%$ both the tensile strength and elongation at break decreased to about half their values recorded for untreated fabrics. This reflects some deterioration of the properties of the fabric upon treatment.

3) Crease recovery angel

Figure 12 shows that the change of the crease recovery angle with the graft yield of the treated viscose rayon fabric. It is clear that the crease recovery angel was significantly improved on increasing the graft yield to $20 \%$.

4) Dyeing properties of the grafted fabrics

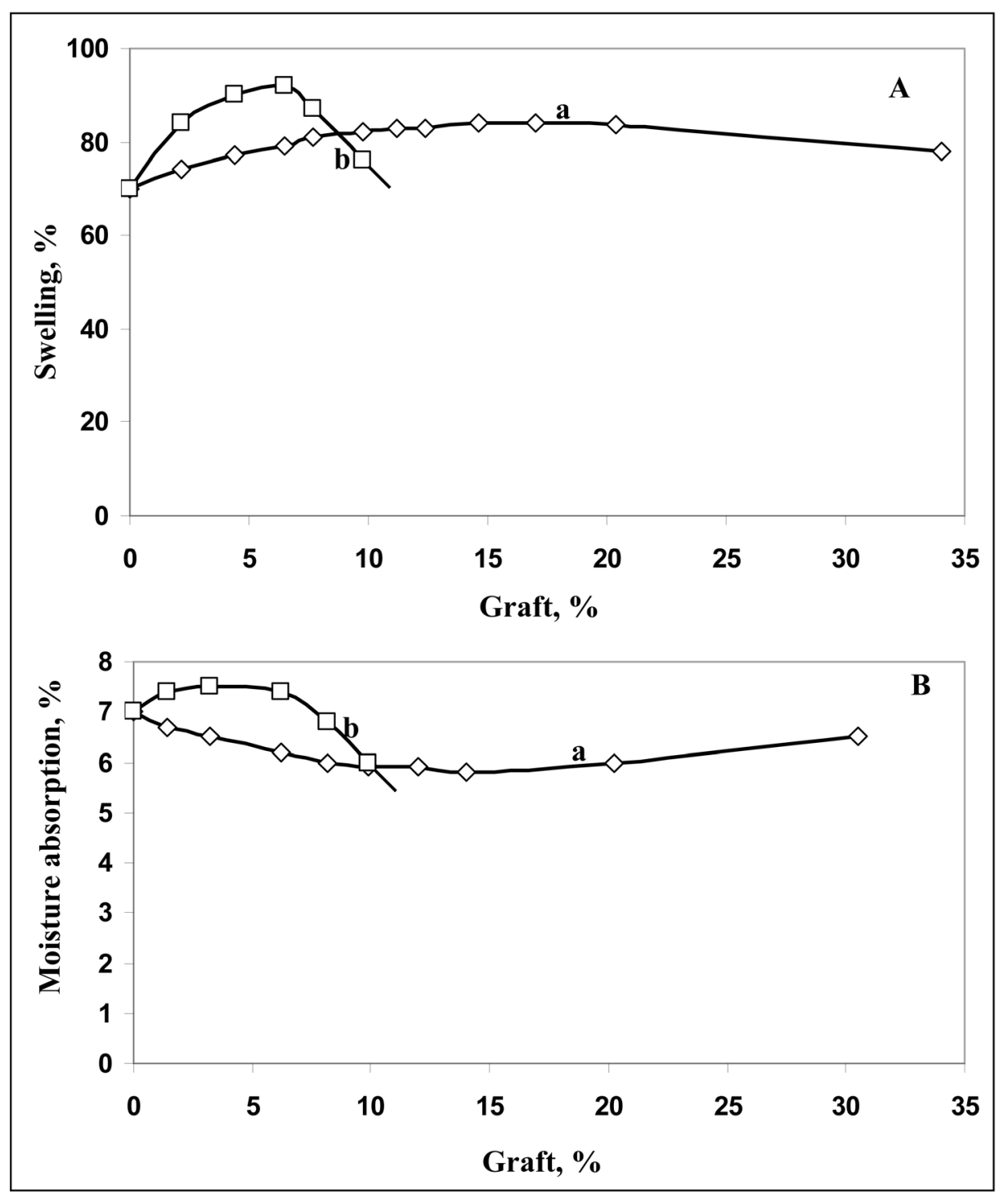

Figure 10. Change of swelling (A) and moisture absorption (B) with the graft yield of acrylic acid onto viscose rayon using different solvent systems: a-Methanol-water (7:2); b-DMF-water (10:3). Irradiation dose: 20 kGy. 


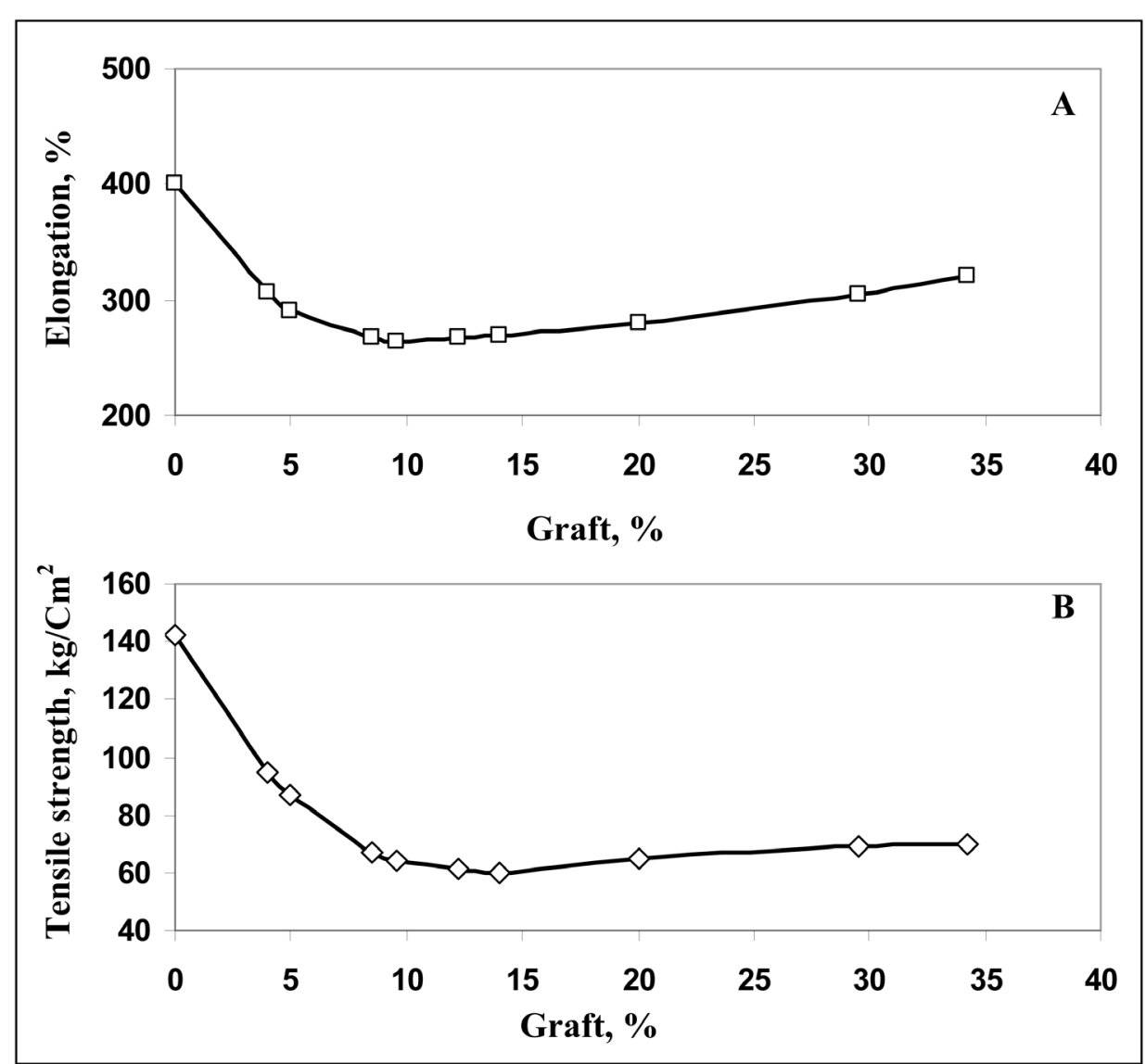

Figure 11. Change of the tensile strength and elongation at break (\%) of viscose rayon sample grafted with acrylic acid with the graft yield. (A) Elongation at break\%; (B) Tensile strength, $\mathrm{kg} / \mathrm{cm}^{2}$. Solvent system: $10 \%$ acrylic acid and $90 \%$ methanol-water $(7: 2)$. Irradiation dose: 20 $\mathrm{kGy}$.

The measured color strength of the dyed grafted fabrics on using three types of dyes are shown in Figure 13. It is clear that on using the direct dye or the disperse dye, no significant changes of the dye uptake were observed on increasing the graft yields. However, on using the basic dye the dye uptake was significantly increased on increasing the grafting yield up to about $20 \%$.

\section{Conclusions}

1) Radiation induced grafting of acrylic acid onto viscose rayon has been successfully carried out.

2) Best grafting conditions were observed when viscose rayon was mutually irradiated with acrylic acid in methanol-water $(7: 2)$ solvent system with the monomer concentration around $10 \%$ of the liquid phase and irradiation dose around $20 \mathrm{kGy}$. Under these conditions the percent grafting amounted to about $13 \%$ and the percent monomer conversion amounted to about $65 \%$.

3) Keeping the irradiated sample tubes after irradiation at room temperature resulted in a significant increase in the grafting yields. Thus, two copolymers were observed. Copolymer A was formed during irradiation and started to decay after stopping irradiation and copolymer B which mainly starts to be formed in the reaction tube after removing the samples away from the irradiation source.

4) On heating the reaction tubes after irradiation the percent grafting significantly increased. Heating at $95^{\circ} \mathrm{C}$ for 4 hours resulted in a 50\% increase in the graft yield as compared to the cold grafting yield while heating for 8 hours resulted in $67 \%$ increase than the value recorded when no heat was applied.

5) Best dying occurred on using the basic dye at a rather wide grafting yield range (up to about $20 \%$ grafting). On the other hand, grafting with acrylic acid did not improve the dyeing properties on using the disperse or the 


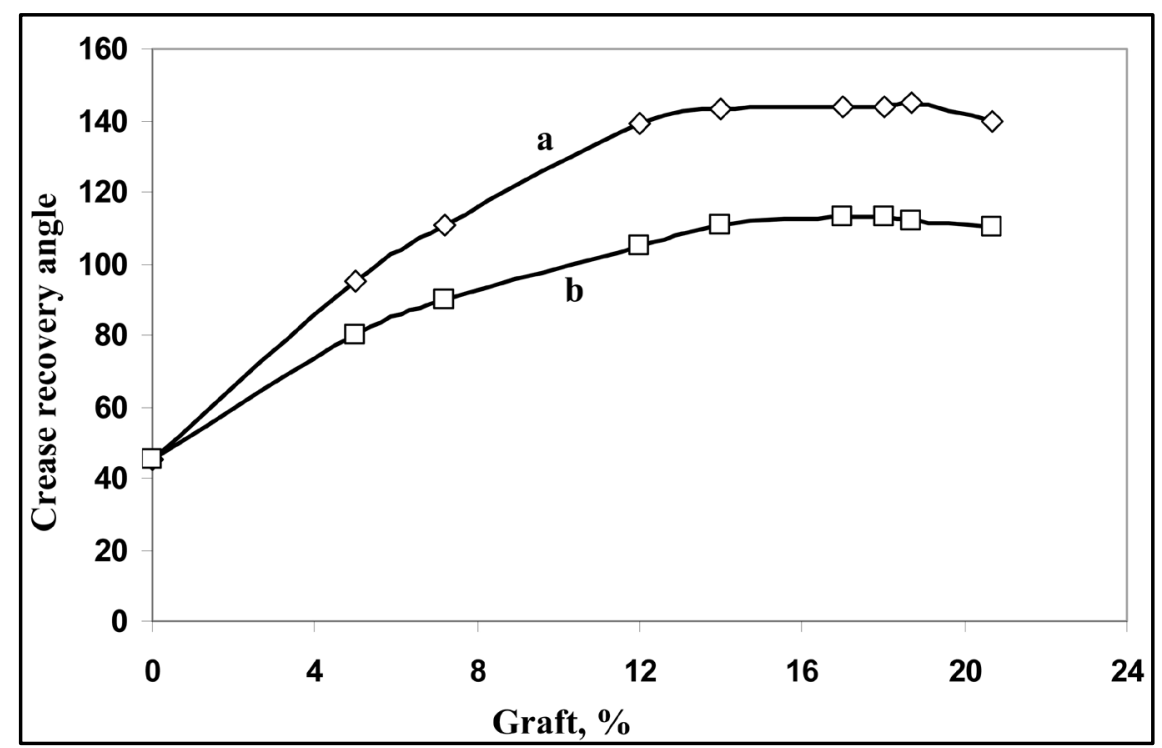

Figure 12. Change of the crease recovery angle with the graft yield (\%) of acrylic acid onto viscose rayon fabrics in the directions: a-Warp direction; b-Weft direction. Solvent system: 10\% acrylic and 90\% methanol-water (7:2). Irradiation dose: $20 \mathrm{kGy}$.

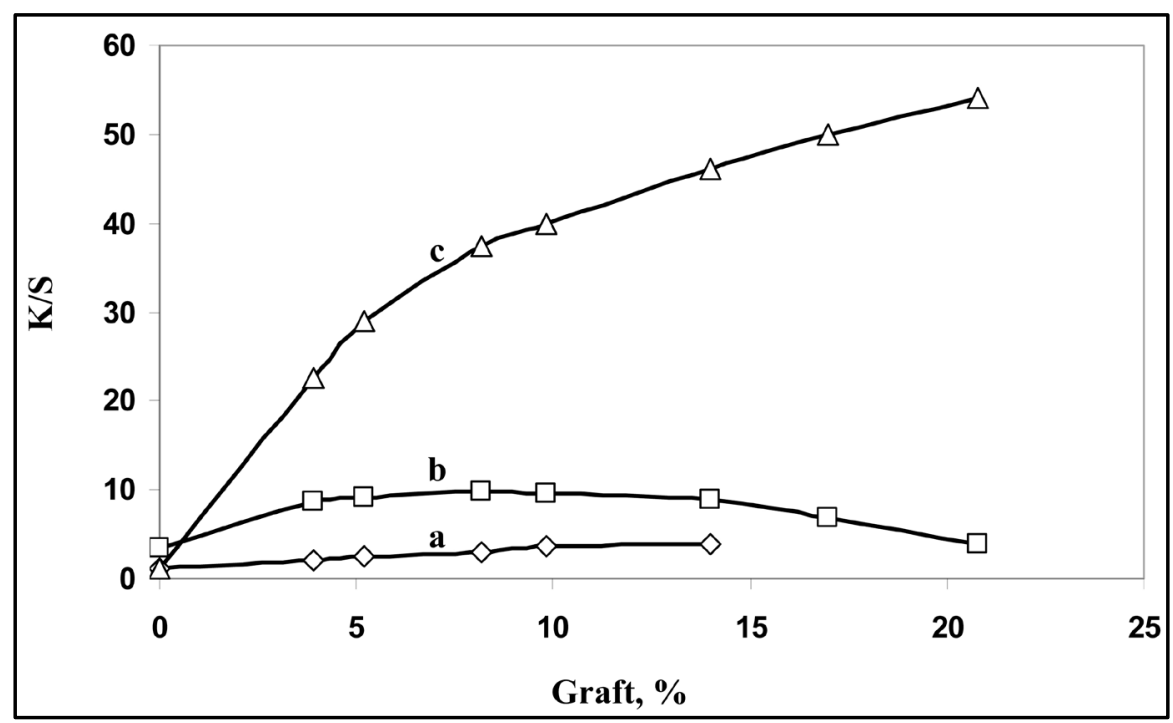

Figure 13. Change of the dye uptake with graft yield of acrylic acid onto viscose rayon using three different dyes: a-Disperse dye; b-Direct dye; c-Basic dye. Irradiation dose: 15 kGy. Solvent system used: DMF- $\mathrm{H}_{2} \mathrm{O}$ : (703).

direct dyes.

\section{References}

[1] Chen, J., Nho, Y.C., Kwon, O.H. and Hoffman, A.S. (1999) Grafting Copolymerization of Acrylamides onto Preirradiated Polypropylene Films. Radiation Physics and Chemistry, 55, 87-92.

http://dx.doi.org/10.1016/S0969-806X(98)00293-X

[2] Abd-El-Rehim, H.A., Hegazy, E.A. and Ali, A.M. (1999) Preparation of Polyvinyl Alcohol Grafted with Acrylic Acid/ Styrene. Journal of Applied Polymer Science, 74, 806-815.

http://dx.doi.org/10.1002/(SICI)1097-4628(19991024)74:4<806::AID-APP6>3.0.CO;2-B

[3] Hegazy, E.A., Abd El-Rehim, H.A. and Shawky, H.A. (2000) Investigation and Charachterisation of Radiation Grafted 
Copolymers for Possible Practical Use in Waste Water Treatment. Radiation Physics and Chemistry, 57, 85-95. http://dx.doi.org/10.1016/S0969-806X(99)00312-6

[4] El-Naggar, A.M., El-Salamawi, K., Ibrahim, S.M. and Zahran, A.H. (1997) Charachterization of Preirradiation Grafting of Acrylamide onto Nylon-6 Fabric. Radiation Physics and Chemistry, 49, 287-295. http://dx.doi.org/10.1016/S0969-806X(96)00136-3

[5] Hsieh, Y., Potter, D. and Elson, M.S. (1984) In-Situ Polymerization of Vinylpyrrolidinone on Nylon 66 by Gamma Radiations. J. Radiat. Curing, 11, 6.

[6] Wilson, J.E. (1974) Radiation Chemistry of Monomers, Polymers and Plastics. Marcel Dekker Inc., New York, 544. 483.http://dx.doi.org/10.1063/1.3128702

[7] El-Salamawi, K.M., El-Naggar, S.H.M. and Zahran, A.H. (1997) Graft Copolymers of Polypropylene Films 1-Radiation Induced Grafting of Mixed Monomers. Polymer International, 42, 225-234. http://dx.doi.org/10.1002/(SICI)1097-0126(199702)42:2<225::AID-PI703>3.0.CO;2-E

[8] Kubelka, P. and Munk, F. (1931) Einbeitrog zur Optidker Farben Striche. Zeitschrift für technische Physik, 12, 593601.

[9] Wilson, J.E. (1974) Radiation Chemistry of Monomers, Polymers and Plastics. Marcel Dekker Inc., New York, 477, 478.

[10] El-Azmirly, M.A., Zahran, A.H. and Barakat, M.F. (1975) Mutual Irradiation Graft Polymerization of Acrylic Acid onto Nylon 6 via Liquid and Vapour Phases. European Polymer Journal, 11, 253. http://dx.doi.org/10.1016/0014-3057(75)90072-5

[11] Jum-Joy, O., Stasiok, H.A., Kocher-Gincheia, L.A., Rozen Blum, N.D., Kokin, A.A. and Rogovin, A.Z. (1962) Khim. Volokna, 5, 12.

[12] Neil, T.O. (1972) Journal of Polymer Science Part A-1 Polymer Chemistry, 10, 569.

[13] Huglin, M.B. and Johnson, B.L. (1969) Role of Cations in Radiation Grafting and Homopolymeriazation. Journal of Polymer Science Part A-1 Polymer Chemistry, 7, 1379-1384. http://dx.doi.org/10.1002/pol.1969.150070601

[14] Wilson, J.E. (1974) Radiation Chemistry of Monomers, Polymers and Plastics. Marcel Dekker Inc., New York, 532, 533.

[15] Shapiro, A. (1962) Radiation Chemistry of Polymeric Systems. Interscience Publishers, New York, 140.

[16] Medvedov, S.S., Korits Koya, O. and Alekseyeva, E. (1943) Zhurnal Fizicheskoi Khimii, 17, 391.

[17] Shapiro, A. (1962) Radiation Chemistry of Polymeric Systems. Interscience Publishers, New York, 361.

[18] Ballentine, D., Glines, A., Adler, G. and Metz, D.J. (1959) Graft Copolymerization by Preirradiation Technique. Journal of Polymer Science, 4, 419. http://dx.doi.org/10.1002/pol.1959.1203412732

[19] Bolt, R.O. and Carol, J.G. (1963) Radiation Effects on Organic Materials. Academic Press, New York, 170.

\section{Submit or recommend next manuscript to SCIRP and we will provide best service for you:}

Accepting pre-submission inquiries through Email, Facebook, LinkedIn, Twitter, etc.

A wide selection of journals (inclusive of 9 subjects, more than 200 journals)

Providing 24-hour high-quality service

User-friendly online submission system

Fair and swift peer-review system

Efficient typesetting and proofreading procedure

Display of the result of downloads and visits, as well as the number of cited articles

Maximum dissemination of your research work

Submit your manuscript at: http://papersubmission.scirp.org/ 